\title{
REDESCRIPTION OF MYXOBOLUS HUNGARICUS JACZÓ, 1940 (MYXOSPOREA: MYXOBOLIDAE), A PARASITE OF BREAM (ABRAMIS BRAMA L.)
}

\author{
K. MOLNÁR ${ }^{*}$ and F. BASKA \\ Veterinary Medical Research Institute, Hungarian Academy of Sciences, \\ H-1581 Budapest, P.O. Box 18, Hungary
}

(Received February 10, 1999; accepted March 18, 1999)

\begin{abstract}
Myxobolus hungaricus Jaczó, 1940 forms relatively large plasmodia on the gills of bream (Abramis brama). The authors give a redescription of this deficiently described parasite on the basis of spores collected from the original habitat, which spores are indicated as a neotype. The plasmodia of the parasite can be found on the gills typically in the spring months, and are located in the central part of the gill filaments. They start to develop in the lumen of capillaries of the secondary lamellae and remain in intralamellar location also after they have reached the mature stage. The spores have a very characteristic shape, as on the surface of the spore valves a distinctly emerging ridge runs parallel to the sutural line. In addition to breams from the typical habitat, Lake Balaton, the plasmodia of M. hungaricus could be detected also on breams originating from the river Danube.
\end{abstract}

Key words: Myxobolus, Myxosporea, redescription, Pisces, Abramis brama

Species of the genus Myxobolus belong to the commonest fish parasites. Their differentiation is based primarily on the morphological characteristics of the spores, as only few data are available on their host specificity, which is a very important property in the case of parasites. At the same time, the precise identification of Myxobolus species is very difficult because of the great similarity of the spores, the shape differences that exist even within a given species, and the incomplete description of some of the species. Of the more easily definable species, Landsberg and Lom (1991) recorded 444 valid species; however, their data will obviously require numerous corrections.

The bream (Abramis brama L.) is one of the commonest fish species of Central Europe, which constitutes the bulk of the fishermen's catch in Lake Balaton. Numerous papers have been published on its myxosporean fauna, and according to Landsberg and Lom (1991) the number of Myxobolus species described from this fish as a typical host reaches 8. In Hungary, Jaczó (1940) was the first to deal with the Myxobolus parasites of this fish: he recorded three

*E-mail: kalman@novell.vmri.hu; Fax: (36-1) 252-1069 
Myxobolus species from the gills of Lake Balaton breams. According to Jaczó (1940), besides the already known M. muelleri two new Myxobolus species occurred on the gills of bream, which he described as new species under the name $M$. hungaricus and $M$. variabilis.

The species described by Jaczó (1940) in Hungarian language have not been recorded from other habitats so far. During our surveys, we often detected the plasmodia of $M$. hungaricus and its spores of unique morphology from the gills of Lake Balaton bream. This paper provides a redescription of that species.

\section{Materials and methods}

The studies were performed from 1994 to 1996, in the framework of an ongoing survey of the parasite fauna of Lake Balaton fishes (Molnár and Székely, 1995). In the fishing season (from March to December) 4-20 breams were examined per month, depending on their availability. A total of 154 breams from Lake Balaton were dissected (60, 41 and 53 in 1994, 1995 and 1996, respectively). The majority were 3 - to 5-year-old specimens selected from the catch of fishermen working with a seine, while the smaller specimens were collected by us with our own nets. For comparison, breams from reaches of the river Danube near Budapest were also examined for the occurrence of Myxobolus infection in 1997. The 14 breams examined were specimens older than 5 years. In all cases, the fish were transported to the laboratory alive, in plastic bags supplied with oxygen, and there they were kept in aerated or through-flow type aquaria and processed gradually within one week. The fish were killed by decapitation and subsequently subjected to complete parasitological examination covering all organs. If Myxobolus plasmodia (cysts) were found, we released the spores from some mature plasmodia and attempted to identify them in live state. In a certain proportion of the cases the spores were recorded on video, then placed into distilled water and stored in refrigerator for further study. Spore dimensions were determined by a computerised video image technique, and images of spores recorded on videotape were transformed into digital images according to the method of Székely (1997). Parallel to these procedures, a few hundred spores were processed into permanent preparations under coverslip in glycerol-gelatin or ammonium picrate. For histological examination, some of the infected gills were fixed in Bouin's solution, embedded in paraffin, and cut into $4 \mu \mathrm{m}$ sections stained with haematoxylin and eosin.

For scanning electron microscopy, some of the spores released from mature plasmodia were washed in saline solution physiological for cold-blooded animals $(0.65 \%)$ and fixed on the surface of coverslips with $2.5 \%$ glutaraldehyde solution adjusted to $\mathrm{pH} 7.2$ with $0.13 \mathrm{M}$ cacodylate buffer, then post-fixed with $1 \%$ buff- 
ered osmium tetroxide solution. After fixation, the preparations were carefully dehydrated in an ascending series of ethanol, then subjected to critical-point drying, coated with a $30 \mathrm{~nm}$ thick gold layer, and examined in a JEOL JSM 35 scanning electron microscope.

\section{Results}

The consistent occurrence of four Myxobolus species (M. bramae Reuss, 1906, M. macrocapsularis Reuss, 1906, M. impressus Miroshnichenko, 1980 and M. hungaricus Jaczó, 1940) was recorded on the gills of Lake Balaton breams during the survey. The majority of plasmodia found on the gills belonged to the species $M$. bramae, but in the spring months $M$. hungaricus, in the late summer months $M$. macrocapsularis, and occasionally $M$. impressus were also detected. (The seasonal dynamics of these species will be reported in another paper.)

The species M. hungaricus Jaczó, 1940 was first detected in Lake Balaton in May and June 1995, when 2 out of 24 fish specimens were infected by that parasite. In 1996, infection was observed only in April, when plasmodia containing mature spores of the parasites were found on 2 out of 8 fish. M. hungaricus occurred also on breams from the river Danube: in April 1997, its spores were collected from 3 out of 9 fish examined.

Unlike M. bramae and M. macrocapsularis forming plasmodia at the end of the gill filaments, the species $M$. hungaricus produced infection at the base or in the central part of the gill filaments. Developing and mature plasmodia could be detected on the fish only during the spring months. By their oval shape and the distinctly emerging ridge running parallel to the sutural line on the surface, the spores (Figs 1 and 2) identified with the species M. hungaricus based upon location and morphology could easily be differentiated from other species known from the bream, both in fresh preparations and in histological sections.

The redescription of the species originally described by Jaczó (1940) incompletely and in Hungarian language is given below on the basis of 50 spores from 4 fish:

Myxobolus hungaricus Jaczó, 1940 (Figs 1-3)

Type host: Abramis brama L.

Site of infection: $\quad$ Basal and central part of the gill filaments.

Type locality: Lake Balaton

Additional locality: $\quad$ River Danube

Prevalence of infection: Lake Balaton: $3.1 \%$ in a whole-year survey and $12.6 \%$ in spring; river Danube: $33 \%$ in spring.

Type material: Neotype deposited in the protozoan collection of the Zoological Department, Hungarian Natural History Museum, Budapest. Collection no.: Prot-4. 
Description of the species. Spores (Figs 1, 2 and 3) pyriform with distinct sutural line. Spore valves symmetrical, without sutural edge markings. A distinctly emerging ridge running parallel with the sutural line is located on the valves (Fig. 3). In lateral view the ridges form characteristic tridentate protrusions at the caudal end (Figs $1 \mathrm{~b}$ and 2). Spores are 11.9 (11.8-12.0) $\mu \mathrm{m}$ long, 7.0 (6.9-7.3) $\mu \mathrm{m}$ wide and $5.0(4.8-5.3) \mu \mathrm{m}$ thick. Two polar capsules pyriform in shape, taper continuously toward the discharging canals of the polar filament. They are closely equal in size, $6.1(5.5-6.5) \mu \mathrm{m}$ long and $2 \mu \mathrm{m}$ wide. The spore has a small triangular intercapsular appendix. Polar filaments loosely coiled with 5 turns in the polar capsule, situated perpendicularly to the longitudinal axis of the capsule. A small distinct iodinophilous vacuole was found in the sporoplasm.
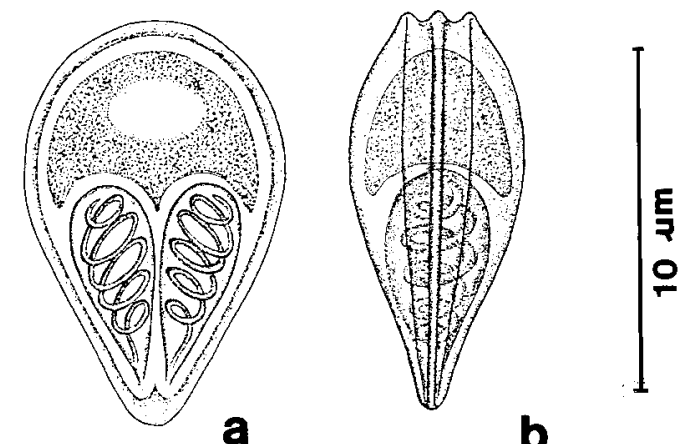

Fig. 1. Schematic drawing of the spore of Myxobolus hungaricus: (a) frontal view; (b) lateral view. $\mathrm{Bar}=10 \mu \mathrm{m}$

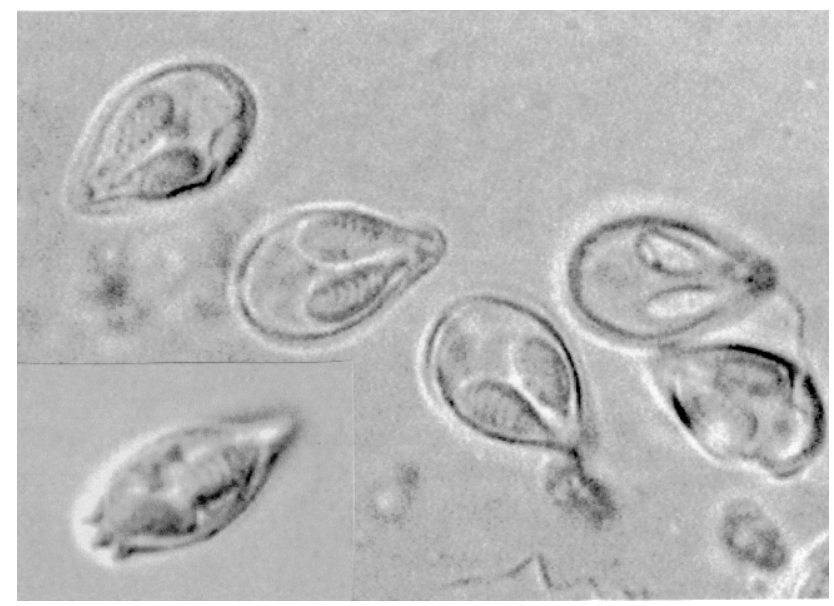

Fig. 2. Spores of Myxobolus hungaricus from a plasmodium collected from the gills of a bream. Digital image, $\times 1800$ 


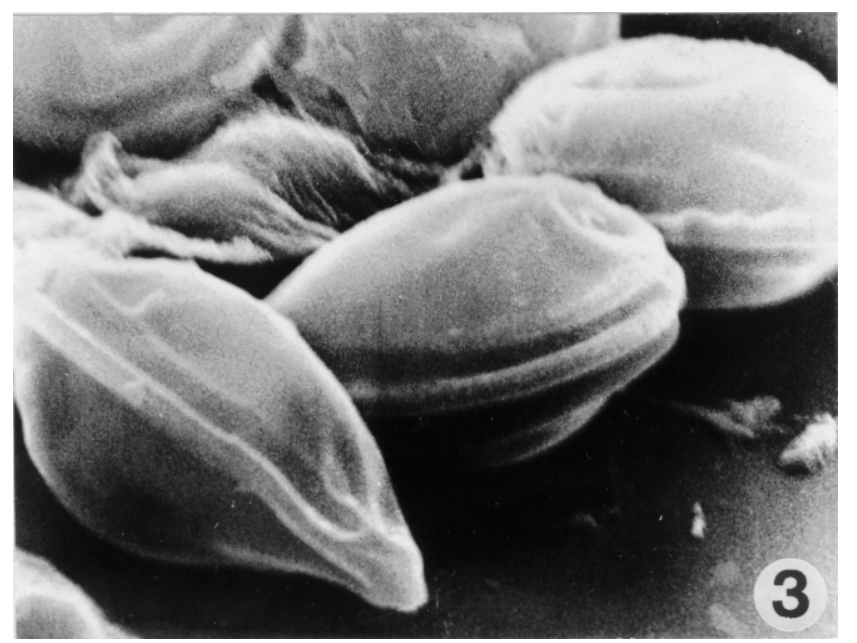

Fig. 3. Scanning electron micrographs of the spores of Myxobolus hungaricus. Note the distinctly emerging ridges running parallel to the sutural line on the two sides, which are best discernible on the anterior end of the spore. $\times 4410$

Differential diagnosis. With its pyriform shape and by having two distinct ridges on the surface of the spores $M$. hungaricus sharply differs from most of the known Myxobolus species of cyprinids. The spores of M. hungaricus are morphologically identical with $M$. elegans Kaschkovsky, a parasite described from Rutilus rutilus; however, the size of $M$. hungaricus spores is smaller than that of $M$. elegans. Similar emerging ridges are found on the surface of $M$. squamalis Iversen, 1954 and M. musajevi Kandilov, 1963, but the shape of the latter species distinctly differs from the spores of $M$. hungaricus.

Histological evidence. In histological sections the young plasmodia were found in the capillaries of the respiratory plates. As a consequence of their $0.35-$ $0.45 \times 0.17-0.35 \mathrm{~mm}$ size, the more mature, round or elliptical, spore-containing plasmodia had dilated the capillary to such an extent that in that condition their origin could no longer be determined. Due to the size of the plasmodium the neighbouring respiratory plates had become flattened and bent back towards the gill filaments (Figs 4 and 5). The stratified epithelium normally found between the respiratory plates had disappeared. Histologically it could be observed that the plasmodium was located in the lumen of a respiratory plate, but the neighbouring respiratory plates also adhered to its wall (Figs 5 and 6). The protruding distal part of the respiratory plate was still discernible on some of the plasmodia growing within the plate, but the majority of mature plasmodia completely filled the respiratory plate. The plasmodia located side by side closely adhered to each other with their wall, the interlamellar epithelium had disappeared, and the space between the plates was filled only by the capillaries of the neighbouring respi- 
ratory plates (Figs 5 and 6 ). The characteristic pyriform shape of the spores was well discernible in the plasmodia also histologically (Fig. 6). It was remarkable that the spore-containing endoplasm was separated from the host tissues by a relatively thick ectoplasm even in the mature plasmodia (Fig. 6). The emptied plasmodium was filled by granulation tissue consisting of connective tissue elements and spores that got stuck in it (Fig. 7).

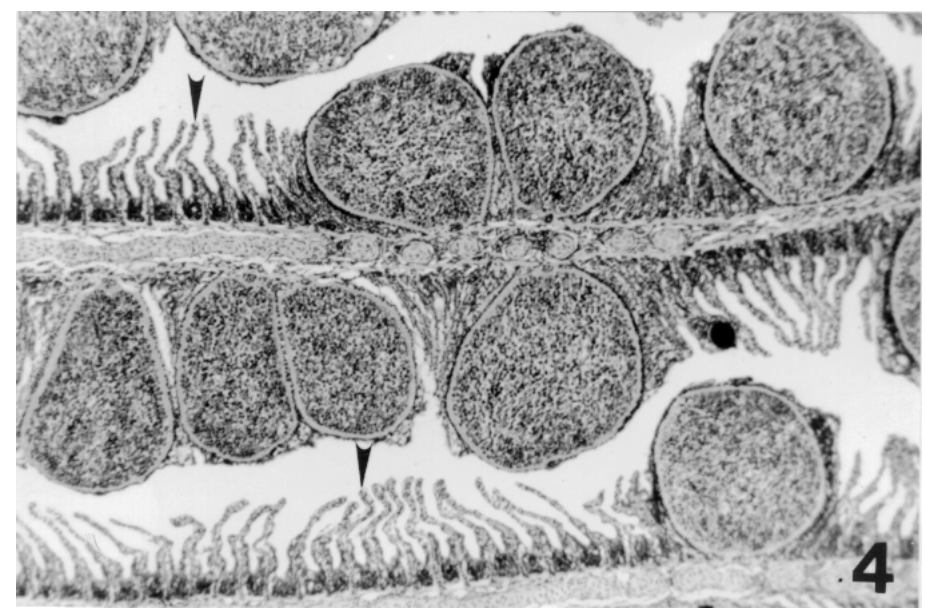

Fig. 4. Myxobolus hungaricus plasmodia filled with spores in the lumen of the respiratory plates of the gill filament. Large sized plasmodia have deformed the neighbouring intact respiratory plates (arrows). Histological section, haematoxylin and eosin (H.-E.), $\times 72$

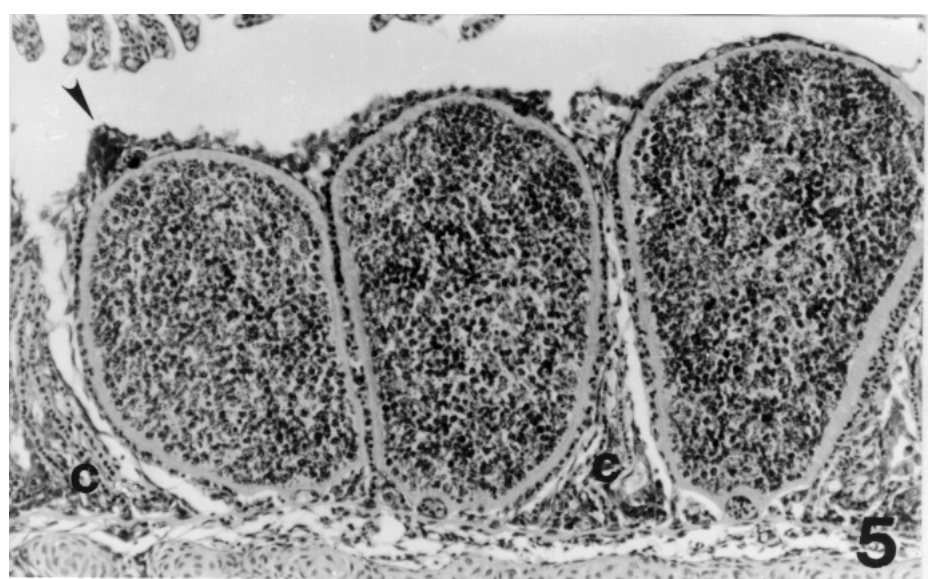

Fig. 5. Myxobolus hungaricus plasmodia developing near each other. On one of the plasmodia the distal end of the attacked respiratory plate is still discernible (arrow). Between and beside the plasmodia the capillaries of the compressed and deformed neighbouring respiratory plates can be seen (c). H.-E., $\times 144$ 


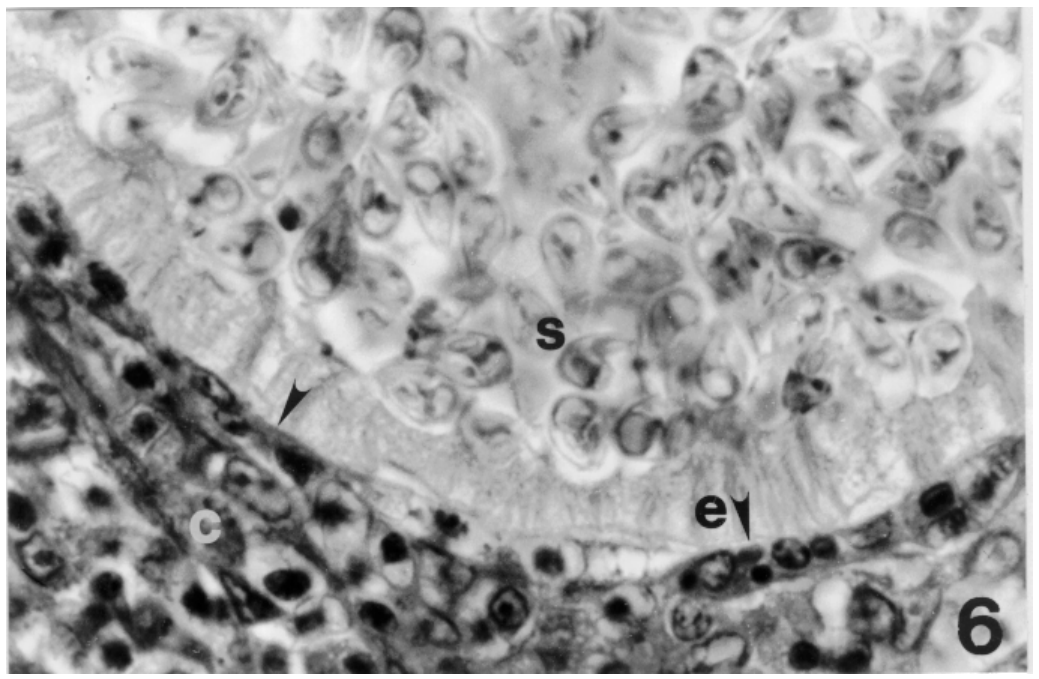

Fig. 6. Basal part of a Myxobolus hungaricus plasmodium that has developed in the capillary network of a respiratory plate. The pyriform spores (s) are well visible in the endoplasm of the plasmodium. The ectoplasm of the plasmodium (e) is strikingly thick. The plasmodium is surrounded by remnants of the infected capillary (arrows) and by capillaries (c) of the compressed neighbouring respiratory plates. Histological section, H.-E., $\times 810$

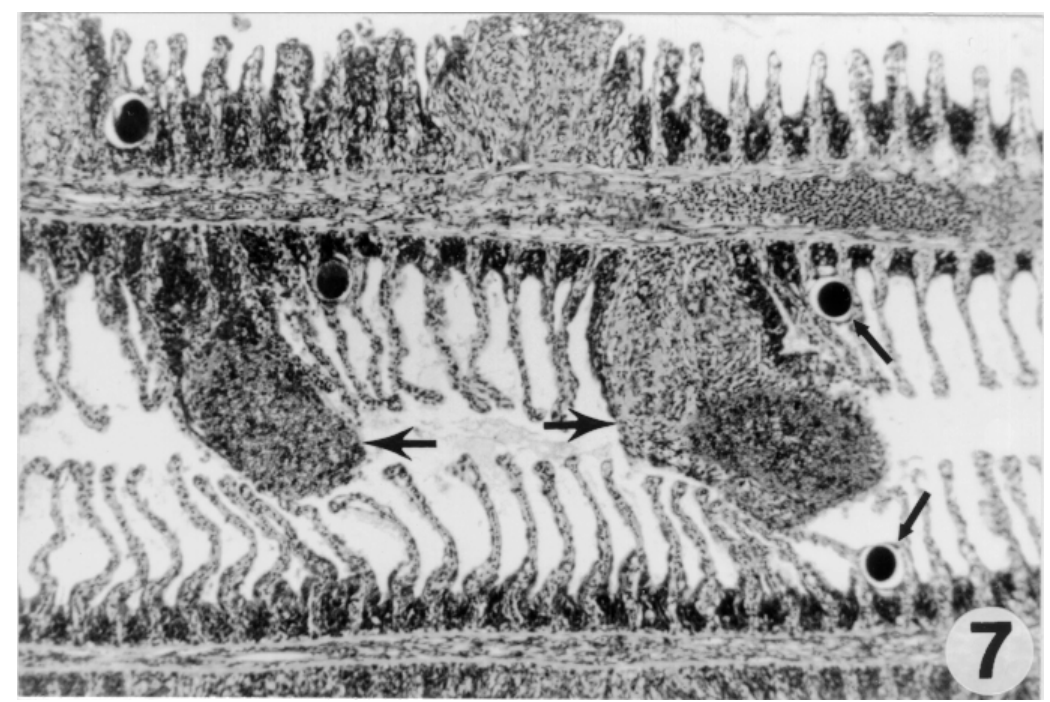

Fig. 7. Disrupted Myxobolus hungaricus plasmodia excreting their spores on the gill filaments (arrows). The place of the plasmodium is occupied by granulation tissue and some spores that have got stuck there. Young mucophilus developmental stages can also be seen in the gill filament as intensely staining round structures (small arrows). Histological preparation, H.-E, $\times 81$ 


\section{Discussion}

The myxosporean fauna of the bream is well studied. Intensive studies on the occurrence of these parasites have been conducted especially in the republics of the former Soviet Union. In their monograph, Donec and Shulman (1984) reported 22 Myxobolus species from bream. Those species, however, do not include $M$. hungaricus. Despite the incomplete original description, the spores isolated from plasmodia developing in the basal and central region of the gill filaments can easily be identified with the species M. hungaricus Jaczó, 1940. By the distinctly emerging ridges located on the surface of the spore and running parallel to the sutural line in lateral direction, this species markedly differs from most of the known Myxobolus species, while in its shape it corresponds to the descriptions published for the species M. elegans Kaschkovsky, 1966. The early description published in Hungarian language must have escaped the specialists' attention; therefore, the spores of $M$. hungaricus found occasionally were identified with other species, first of all with M. elegans Kaschkovsky. Among the hosts of this latter species Kaschkovsky (1966) listed the orfe (Leuciscus idus) in addition to the roach (Rutilus rutilus) serving as typical host. Despite the morphological identity of $M$. hungaricus and $M$. elegans and the unquestionable priority of $M$. hungaricus, the existence of $M$. elegans as a valid species cannot be queried in view of the slight spore size differences existing between the Hungarian data (Jaczó, 1940; our own measurements) and the data published by Russian authors (Kaschkovsky, 1966; Shulman, 1966; Donec and Shulman, 1984). In addition to the variation in size, another substantial difference is that $M$. hungaricus and $M$. elegans have been described from hosts belonging to different genera. At the same time, the spores recorded by Donec and Shulman (1984) from bream but identified as M. elegans should be regarded as those belonging to $M$. hungaricus. The species $M$. hungaricus is a parasite characterised by strict seasonality, the occurrence of which has to be reckoned with in the spring months only. Although its overall prevalence in the total bream population examined can be considered low because of this seasonality, in the spring months the occurrence of this parasite is not rare.

Although it is a relatively little known parasite, $M$. hungaricus belongs to those few species which have a known extrapiscine, 'intraoligochaete' development, as El-Mansy and Molnár (1997) have experimentally studied its development resulting in the appearance of actinospores of triactinomyxon type.

The histological examinations have clearly proved that the plasmodia of $M$. hungaricus start their development in the blood vessels of the gills, and that the wall of the growing plasmodia is constituted by the endothelium and epithelium of the respiratory plates. As regards its location, M. hungaricus fully conforms to the type of development designated by Current and Janovy (1976) as 
intralamellar. The results obtained in this study do not allow us to draw conclusions as to the pathological importance of the parasite.

\section{Acknowledgements}

The authors would like to thank Dr Csaba Székely and Ms Emese Papp for their help in collection and dissection of the fish, Éva Zsély for making the histological preparations, and Edit Eszterbauer for her help with the video technique. This study was rendered possible by grants of the Hungarian Scientific Research Fund, projects no. T020044 and T019911, and by financial support received from the Department of Hunting and Fisheries of the Ministry of Agriculture and Rural Development.

\section{References}

Current, W. L. and Janovy, J. (1976): Comparative study of ultrastructure of interlamellar and intralamellar types of Henneguya exilis Kudo from channel catfish. J. Protozool. 25, 56-65.

Donec, Z. S. and Shulman, S. S. (1984): Cnidosporidia. In Bauer, O. N. (ed.) Key to Parasites of Freshwater Fishes of the USSR (in Russian). Nauka, Leningrad, Vol. I, pp. 88-251.

El-Mansy, A. and Molnár, K. (1997): Development of Myxobolus hungaricus (Myxosporea: Myxobolidae) in oligochaete alternate hosts. Dis. Aquat. Org. 31, 227-232

Jaczó, I. (1940): Studies on the myxosporidians of Lake Balaton fishes (in Hungarian). Magyar Biol. Kut. Munkái 12, 227-290.

Kaschkovsky, B. B. (1966): Myxobolus elegans sp. n. In: Shulman, S. S. (ed.) The Myxosporidian Fauna of the USSR (in Russian). Nauka, Moscow-Leningrad, pp. 443-444.

Landsberg, J. H. and Lom, J. (1991): Taxonomy of the genera of the Myxobolus/Myxosoma group (Myxobolidae: Myxosporea), current listing of species and revision of synonyms. Syst. Parasitol. 18, 165-186.

Molnár, K. and Székely, Cs. (1995): Parasitological survey of some important fish species of Lake Balaton. Parasit. Hung. 28, 63-82.

Shulman, S. S. (1966): The Myxosporidian Fauna of the USSR (in Russian). Nauka, MoscowLeningrad. $504 \mathrm{pp}$.

Székely, Cs. (1997): Possible applications of video technology and digital image processing in fish parasitology: Morphological examination of the groups Apicomplexa and MyxosporeaActinosporea by video technology. Bull. Eur. Ass. Fish Pathol. 17, 81-82. 